1,2,3,4 Kahramanmaraş Sütçü Imam Üniversitesi Tıp Fakültesi KBB Anabilim Dalı, Kahramanmaraş, Türkiye

1 e-posta: mgyctf23@gmail.com ORCID: 0000-0002-1880-0685

2e-posta:

israfilorhan@ksu.edu.tr ORCID: 0000-0002-9557-7050

${ }^{3}$ e-posta:

drirfankara@gmail.com ORCID: 0000-0002-1880-0685

${ }^{4}$ e-posta:

nagihanbilal@ksu.edu.tr ORCID: 0000-0002-2850-3481

Atıf İçin: Muhammed Gazi YILDIZ, İsrafil ORHAN, İrfan KARA, Nagihan BiLAL, Servikal

Vagal Schwannom: Olgu Sunumu, Balıkesir Medical Journal, 2020;4(2): 23-28

Başvuru Tarihi: 11.03.2020

Kabul Tarihi: 09.06.2020 Yayınlanma Tarihi: 23.06.2020

Sorumlu Yazar:

Muhammed Gazi YILDIZ, Kahramanmaraş Sütçü İmam Üniversitesi Tıp Fakültesi KBB Anabilim Dalı, Kahramanmaraş,

Türkiye e-posta: mgyctf23@gmail.com

\section{Servikal Vagal Schwannom: Olgu Sunumu}

\author{
Cervical Vagal Schwannom: Case Report
}

Muhammed Gazi YILDIZ ${ }^{1}$, İsrafil ORHAN ${ }^{2}$, İrfan KARA ${ }^{3}$, Nagihan BILAL $^{4}$

\section{Öz}

Schwannomlar (nörilemmoma) periferik, kranial ve otonomik sinirleri saran schwann hücrelerinden köken alan benign, kapsüllü, soliter ve yavaş büyüyen kitlelerdir. Bu tümörlerin $\% 25-45^{\prime} i$ baş boyun bölgesinde gözlenir. Vagal sinir kaynaklı schwannomlar ise nadir görülen neoplazmlardandır. Elli yedi yaşında erkek hasta, 6 yıldan beri boyunda şişlik şikâyeti nedeni ile kliniğimize başvurdu. Boyun Manyetik Rezonans görüntülemesinde (MRG), tuz biber görünümü olan yaklaşık $6 \times 8 \mathrm{~cm}$ boyutlarında kistik kitle olduğu görüldü. Intraoperatif olarak kitlenin vagal sinirden köken aldığı izlendi.

Baş boyun schwannomları, özellikle de kistik vagal schwannomlar nadir görülmekle birlikte boyun kitlelerinin ayırıcı tanısında düşünülmelidir.

Anahtar Kelimeler: schwannoma; vagus; baş ve boyun neoplazileri

\section{ABSTRACT}

Schwannomas are benign, encapsulated, solitary and slow growing masses which surround peripheral, cranial and autonomic nerves. Twenty-five to forty-five percent of these tumors are seen at the head and neck. Cystic vagal schwannomas are very rare. Fifty-seven-year-old man presented to our clinic with a painless right neck mass which had grown during 6 years. Neck Magnetic Resonance Imaging reported a mass of approximately $6 \times 8 \mathrm{~cm}$ with salt and pepper pattern. The mass was originated from vagal nerve.

Head and neck cystic vagal schwannomas are rare and should be considered in the differential diagnosis of neck masses.

Keywords: schwannoma; vagus nerve; head and neck neoplazm 
Schwannomlar, periferik sinir kılıfı içerisinde bulunan schwan hücrelerinden kaynaklanan, nadir, iyi huylu, kapsülü olan tümörlerdir (1). Schwannomlar kranial sinirler, servikal ve brakial pleksus, sempatik ve parasempatik zincirleri içeren herhangi bir nöral yapıdan gelişebilir (2). Nadir izlenen servikal vagal schwannom genellikle yavaş progresyon gösteren, benign karakterli bir tümör olup yaşamın 3-5. dekatlarında daha sık görülür (3). Schwannomlarda kistik dejenerasyon ve nadiren de malign formasyon izlenebilir (4). Bu olguda boyunda, vagal sinir kaynaklı kistik schwannom olgusu literatür bilgileri eşliğinde sunulmuştur.

\section{OLGU SUNUMU}

Elli yedi yaşında erkek hasta boyun sağ tarafında altı yıl önce başlayan, son beş aydır büyüyen, ağrısız şişlik şikâyeti ile kliniğimize başvurdu. Yapılan fizik muayenesinde sağ juguloomohyoid bölgeyi dolduran, sağ supraklavikuler fossa ve jugulodigastrik bölgeye uzanım gösteren yaklaşık $6 \times 8 \mathrm{~cm}^{\prime}$ lik palpasyonla elastik kıvamlı, düzgün yüzeyli, kitlesel lezyon tespit edildi. Endoskopik muayenede nazofarinks, larinks ve vokal kord hareketlerinin doğal olduğu izlendi. Hastanın boyun ultrasonografisinde (USG) karotid kılıfı içine yerleşim gösteren $8 \times 8 \mathrm{~cm}$ boyutlarında, semisolid komponenti olan, ovoid, hipoekoik kitlesel lezyon tariflendi. Doppler incelemesinde kitle ile ilişkili belirgin vaskülarite olmadığı raporlandı. Manyetik rezonans (MRG) görüntülemesinde sağ sternokleidomastoid kas medialinde yerleşim gösteren, larengeal yapılara bası yapan, yaklaşık $6 \times 8 \mathrm{~cm}$ 'lik kontrast tutmayan, heterojen, kistik komponenti olan kitlesel lezyon tespit edildi. Kitlenin sağ karotis kılıfı bitişiğinde, düzgün sınılı ve tuz biber manzarasının olması schwannom ile uyumlu olabileceği rapor edildi (Resim 1). Hastaya iki defa ince iğne aspirasyon biyopsisi (iiAB) yapıldı ancak non-diagnostik materyal olarak raporlandı. MR Anjiografik görüntülemesinde sağ internal ve eksternal karotid arterler arasındaki deplasman (Lir belirtisi) dışında vasküler yapı kaynaklı kitlesel lezyon izlenmedi (Resim 2).

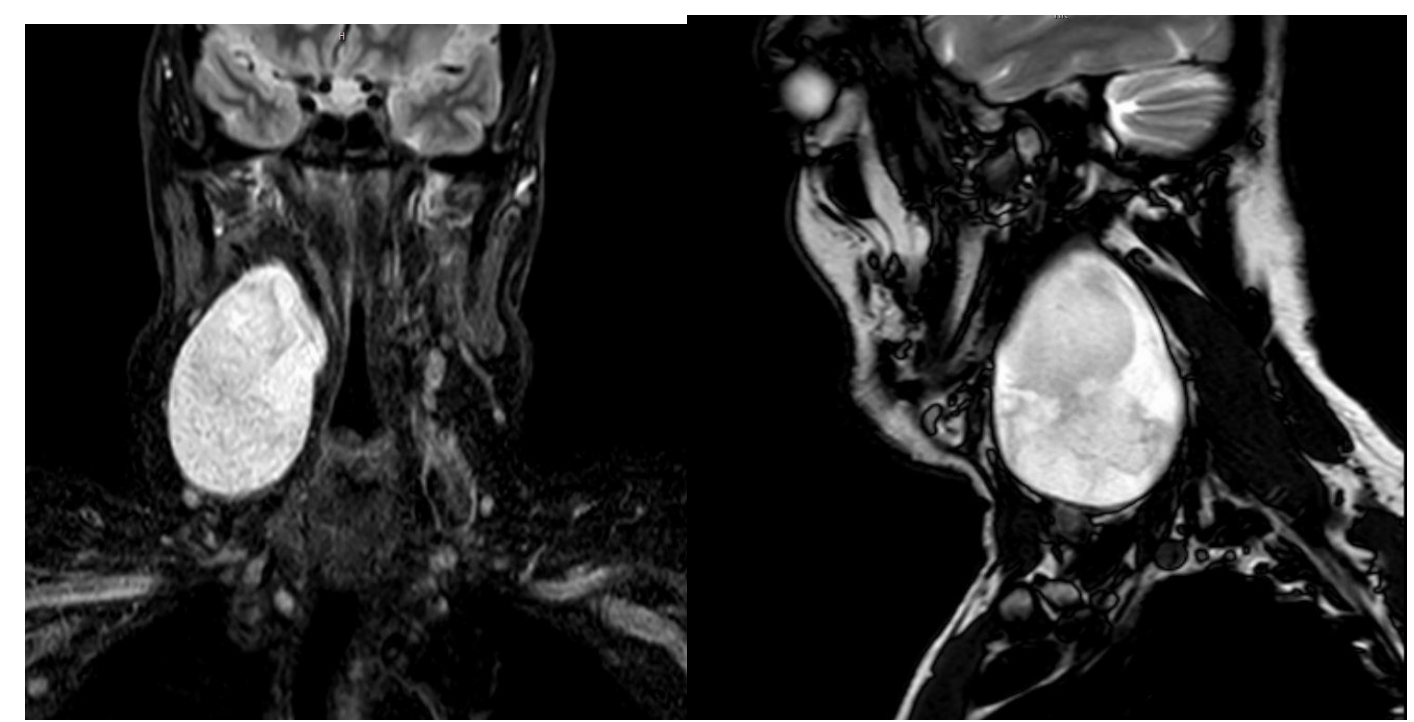

Resim 1. Boyun Manyetik Rezonans görünütülemede, koronal ve sagittal planda yaklaşık $6 \times 8 \mathrm{~cm}$ boyutlarındaki kitlenin tuz biber manzarası görüntüsü.

Kitlenin total eksizyonuna karar verildi. Hasta yapılacak cerrahi müdahaleyi takiben oluşabilecek Horner sendromu, yutma güçlüğü, ses kısıklığı gibi komplikasyonlar hakkında bilgilendirildi. Boyun 
eksplorasyonu yapılarak total eksize edilen kitlenin sarımtırak-beyaz renkli olduğu, kommon karotid arter ve juguler venin bitişiğinde, vagal sinir orjinli olduğu izlendi (Resim 3).

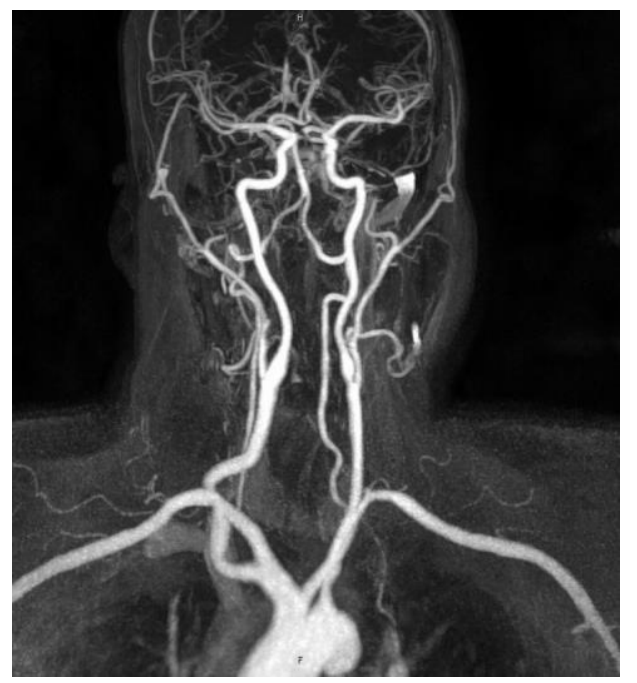

Resim 2. Manyetik Rezonans Anjiografide kitlenin sağ internal ve eksternal karotid arterleri mediale doğru deplase ettiği izlenmekte.

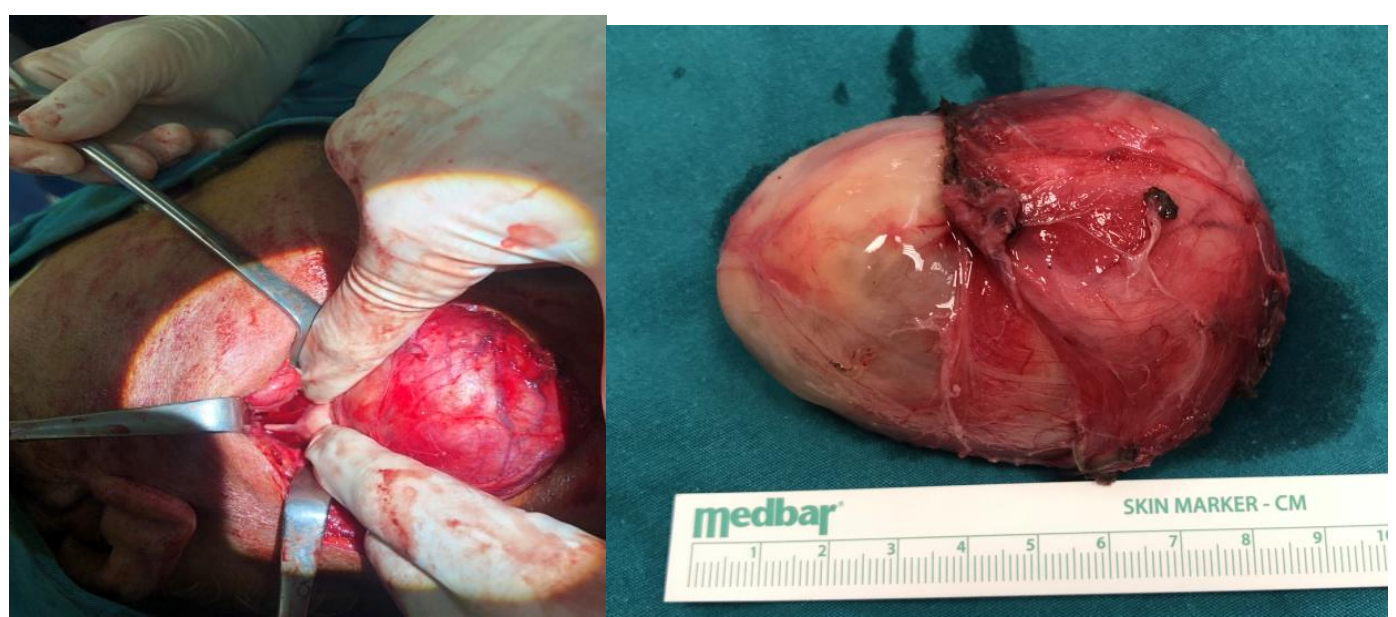

Resim 3. Kitlenin intraoperatif N.Vagus ile ilişkisi ve postoperatif görüntüsü.

İntraoperatif gözlemde kitlenin büyük olması, tamamen vagal sinir liflerinden gelişmesi nedeni ile kitle vagus sinirinden disseke edilemedi ve en-blok şeklinde vagal sinir kesilerek çıkarıldı. Materyalin histopatolojik incelemesinde kapsüllü, kısmen kistik alanları ve semisolid komponenti de bulunan, hücreden zengin elonge çekirdekli iğsi hücre (Verocay cisimciği) demetlerinden olusan Antoni A alanları ve hücreden yoksun gevşek dokudan olusan Antoni B alanları olduğu izlendi. Immunohistokimyasal yöntemle uygulanan S-100 pozitif bulunarak tanı doğrulandı. Ameliyat sonrası erken dönemde sağ vokal kord paralizisi izlendi ve ses kısıklığı yaşayan hastaya ses terapisi önerilerek takibe alındı. Hasta postoperatif altıncı ayında olup vokal kord paralizisi devam etmekte ve ameliyat bölgesinde herhangi bir sorun bulunmamaktadır.

\section{TARTIŞMA}

Schwannomlar iyi huylu, kapsülü olan, yavaş progresyon gösteren soliter kitlelerdir. Her yaşta görülebilmeleri ile birlikte en sık 30-50 yaslar arasında görülürler (5). Hastalar genellikle boyun bölgesinde ağrısız şişlik şikâyeti ile başvururlar. Bununla birlikte ağrı, hassasiyet, üzerine bası ile oluşan öksürük, baş ağrısı, 
kranial sinir paralizileri (özellikle 5,6,7,12. sinir), Horner sendromu, çınlama, işitme kaybı gibi nörolojik bulgularla da başvurabilirler (6). Olgumuz 57 yaşında olup ağrısız ve giderek büyüyen kitle şikâyeti ile başvurmuştu.

Sinir kılıfı tümörleri için birçok görüntüleme yöntemi kitlenin yapısı hakkında bilgi vermektedir. USG schwannomun kaynaklandığı sinirin trasesini ve kitlenin natürü hakkında yeterli bilgi verebilir. Doppler incelemesinde ise tromboze anevrizmadan dev lenfadenomegaliye kadar geniş yelpazedeki ayırıcı tanıda düşünülmesi gereken lezyonların ekartasyonunda yardımcı olmaktadır (7). Literatürde schwannomlar farklı yapıları (heterojen ve homojen) ile bilgisayarlı tomografide hipodens, izodens ve hiperdens olarak tanımlanmıştır. Heterojenite; kistik dejenerasyon, ksantomatöz değişiklik ile sellüler veya kollajenöz bölgelere komşu rölatif hiposelüleriteye bağlanmaktadır. Manyetik rezonans görüntülemede T1 ağırlıklı görüntülemelerde hipointens ve T2 ağırlıklı görüntülemelerde ise hiperintens görüntüler dikkat çekmektedir. Schwannomlara spesifik olmamakla birlikte karakteristik bulgu olarak kabul edilen tuz biber manzarası da MRG bulguları arasındadır $(7,8)$. Servikal vagal schwannomlarda tipik MRG bulgularından biri de kitlenin internal juguler ven ve karotid arter arasında yerleşmesidir. Furuwaka ve ark. ${ }^{9}$ yapmış olduğu çalışmada servikal vagal schwannom ve sempatik zincir kaynaklı schwannomların MRG bulguları incelenmiş, servikal vagal schwannomlarda kitlenin internal juguler venin mediale, karotid arterin ise laterale doğru yer değiştirdiği tespit edilmiştir. Sempatik zincir kaynaklı schwannomlarda ise internal juguler ven ve karotid arteri ayırmadan deplase ettiği rapor edilmiştir. Olgumuzda kitlenin internal ve eksternal karotisi mediale doğru belirgin şekilde deplase ettiği ayrıca karakteristik bulgu olarak görülen tuz-biber manzarası tespit edildi. Operasyon öncesi tanıda ince iğne biyopsisini düşük duyarlılığına rağmen öneren çalışmalar da mevcuttur $(10,11)$. Bizim olgumuzda ise iïAB'nin tanısal değerinin olmadığı görüldü.

Vagal schwannomlar genellikle radyorezistanstır ve tedavide öncelikli yaklaşım cerrahidir (12). Cerrahide en önemli adım tümörün vagal sinirden disseksiyonu ve vagal sinirin korunmasıdır. Ancak cerrahi sırasında kitlenin sinir gövdesi ile yapışık olması, teknik açıdan sinirin korunmasının mümkün olmadığı durumlarda kitlenin en-blok rezeksiyonu ve sinirin uç uca anastomozu önerilen bir prosedür olarak karşımıza çıkmaktadır. Sinir anastomozu kitlenin sinir ile ilişkisine bağlı olup bu prosedürde klinik açıdan postoperatif vokal kord paralizisi sıklıkla izlenmektedir $(11,13,14)$. Ses kısıklığı preoperatif dönemde az görülmekle birlikte genellikle postoperatif dönemde oluşmaktadır. Bu nedenle preoperatif indirekt laringoskopik muayene ile vokal kordların hareket durumu mutlaka tespit edilmelidir $(11,15)$. Ses kısıklığı gelişen olgularda ses terapisi, vokal kord medializasyonu gibi tedavi seçenekleri gündeme gelmektedir. Olgumuzda preoperatif vokal kord hareketleri doğal iken postoperatif sağ vokal kord lateral pozisyonda paralitik izlendi.

Verocay, schwannomun ilk patolojik tanımlanmasını yapmıştır. Histolojik olarak, schwannomlar 2 tipte izlenir: Antoni tip A ve Antoni tip B. Antoni tip A (fasiküllü) formu; iğ şeklindeki hücrelerin çekirdeklerinin dizilimiyle oluşan palizat paternle karekterizedir. Antoni tip B (retiküler tip) miksoid alanlar içeren daha gevşek bir yapıya sahiptir (16). Schwannomlar, gerçek fibröz kapsülü olan tümörlerdir (17). Nekroz, kistik dejenerasyon ve fokal tromboz sıklıkla gözlenen bulgulardandır. Immunohistokimyasal boyamada schwannomlara spesifik olarak S-100 proteini (sinir sistemi destek hücrelerine özgü nöral krest antijeni) ekspresyonu fazla bulunur. 
Schwannomlarda musinöz dejenerasyon, hemoraji, nekroz ve mikrokist formasyonundan dolayı tümör içerisinde kistik formasyon gözlenebilir (16).

Ayırıcı tanıda karotid cisim tümörü, lenfadenomegali, tiroid nodülü ya da tiroid kisti, brankial kist, teratom, dermoid kist, lipom, minör tükrük bezi tümörü, metastatik kitle ve nörofibrom göz önünde bulundurulmalıdır (18). Karotid kılıfı tümörü, brankial kleft kisti, dermoid kist gibi kitlelerle radyolojik olarak ayırım yapılabilirken, nörofibrom ile ayrıcı tanıda patolojik bulgular ön plana çıkar (19).

Sonuç olarak benign tümör olarak bilinen vagal schwannomlarda tek tedavi seçeneği cerrahidir. Bu tümörlerin progresyon gösterebileceği ve malign transformasyonun nadir de olsa gerçekleşebileceği dikkate alınmalıdır. Tümörün kaynaklandığı nöral yapı ile yakın ilişkide olduğu bazı olgularda ameliyata sekonder disfaji, Horner sendromu ve vokal kord paralizisi gibi ciddi morbiditeler izlenebilir. Bu sebeple bazı otörler tümör eksizyonu açısından semptom verene kadar beklenebileceğini belirtmektedirler.

\section{KAYNAKLAR}

1. Myers E, Johnson J. Neoplasms. In: Cummings CW, ed. Otolaryngology Head and Neck Surgery. 4th ed. Philadelphia: ElsevierMosby; 1998;25(8):1727-1728.

2. Mevio E, Gorini E, Sbrocca M, Artesi L, Mullace M, Castelli A, Migliorini L. Unusual cases of cervical nerves schwannomas: phrenic and vagus nerve involvement. Auris Nasus Larynx 2003;30(2):209-213.

3. Colreavy MP, Lacy PD, Hughes J, Bouchier-Hayes D, Brennan P, O’Dwyer AJ, Donnelly MJ, Gaffney R, Maguire A, O'Dwyer TP, Timon CV, Walsh MA. Head and neck schwannomas - a10-year review. J LaryngolOtol 2000;114:119-124.( PMID:10748827)

4. Sarıoğlu S, Özkal S, Güneri A, Ada E, Sis B, Erdağ TK, Pabuççuoğlu HU. Cystic schwannoma of the maxillary sinus. AurisNasus Larynx 2002;29:297-300.

5. Mierzwiński J, Wrukowska I, Tyra J, Paczkowski D, Szcześniak T, Haber K. Diagnosis and management of pediatric cervical vagal schwannoma. Int J Pediatr Otorhinolaryngol. 2018 Nov;114:9-14.

6. Cunningham LL, Warner MR. Schwannoma of thevagus nevre first diagnosed as a parotid tumor. J Oral Maxillofac Surg 2003; 61:141-144.

7. Beggs I. Sonographic appearances of nerve tumors. JClinUltrasound 1999;27:363.

8. 8-)Anil G, Tan TY. Imaging characteristics of schwannoma of the cervical sympathetic chain: a review of 12 cases. Am J Neuroradiol 2010;31(8):1408-1412.( PMID:20616174)

9. Furukawa M, Furukawa MK, Katoh K, Tsukuda M. Differentiation between schwannoma of the vagus nerve and schwannoma of the cervical sympathetic chain by imaging diagnosis. Laryngoscope 1996;106:1548-1552. (PMID:8948621)

10. Zhang H, Cai C, Wang S, Liu H, Ye Y, Chen X. Extra cranial head and neck schwannomas: A clinical analysis of 33 patients. Laryngoscope 2007;117:278-281.

11. Liu HL, Yu SY, Li GK, Wei WI. Extracranial head and neck Schwannomas: a study o the nerve of origin. Eur Arch Otorhinolaryngol 2011; 268:1343-1347

12. Elsharkawy M, Xu Z, Schlesinger D, Sheehan JP. Gamma Knife surgery for nonvestibular schwannomas: radiological and clinical outcomes.J Neurosurg 2012;116:66-72. 
13. Sandler ML, Sims JR, Sinclair C, Sharif KF, Ho R, Yue LE, Téllez MJ, Ulkatan S, Khorsandi AS, BrandweinWeber M, Urken ML. Vagal schwannomas of the head and neck: A comprehensive review and a novel approach to preserving vocal cord innervation and function. Head Neck. 2019 Jul;41(7):2450-2466.

14. Balci MK, Ciger E, Işlek A, Arslanoglu S, Onal HK, Eren E. Baş Boyun Schwannomlarında Klinik Tanı ve Total Cerrahi Rezeksiyon ile Tedavi Sonuçları. KBB-Forum 2020;19(1):039-046

15. Schwam ZG, Kaul VZ, Shrivastava R, Wanna GB. Purely intracranial vagal schwannoma: A case report of a rare lesion. Am J Otolaryngol. 2019 May - Jun;40(3):443-444.

16. Morrissey MSC, Sellars SL. Vagal nerve schwannoma - a new diagnostic sign. Postgrad Med J 1990;66(771):42-43.

17. Corroller TL, Sebag F, Vidal V, Jacquier A, Champsaur P, Bartoli JM, Moulin G. Sonographic diagnosis of a cervical vagal schwannoma. J Clin Ultrasound 2009;37(1):57-60.( PMID:18386823)

18. Cavallaro G, Pattaro $G$, lorio $O$, et al. A literature review on surgery for cervical vagal schwannomas. World J Surg Oncol. 2015;13:130.

19. Cakmak O, Yavuz H, Yucel T. Nasal and paranasal sinus schwannomas. Eur Arch Otorhinolaryngol 2003;260:195-197. (PMID:12709802) 